\title{
Factors That Impact on Rural and Remote Students' Participation in Higher Education
}

\author{
Delwar Hossain \\ Centre for Rural and Remote Area Health, University of Southern Queensland, Qld, Australia \\ Email: delwar.hossain@usq.edu.au \\ Don Gorman \\ Faculty of Science University of Southern Queensland, Qld, Australia \\ Email: don.gorman@usq.edu.au
}

Jill Lawrence

Faculty of Arts, School of Humanities and Communication, University of Southern Queensland Qld, Australia

Email: jill.lawrence@usq.edu.au

Lorelle Burton

Faculty of Sciences, Psychology, University of Southern Queensland, Qld, Australia

Email: lorelle.burton@usq.edu.au

\begin{abstract}
This paper aims to explore the factors that impact on rural and remote students' participation in higher education at university. The findings indicated that the students were familiar only with university scholarships, tertiary preparation program, and head start. Before admission, most students required information on pathways to university, admission requirements, scholarships, and range of courses and after admission they required information on academic support, tutorial assistance, library and IT services. This paper also suggests that universities need to evaluate the effectiveness of the services they offer to both attract and support rural and remote students to University if participation rates are to be raised.
\end{abstract}

Index Terms - Students, Admission, Higher education, Scholarship, Performance, Academic support

\section{INTRODUCTION}

Education involves producing desirable changes in knowledge, skills and attitudes of learners and the university strategic plan includes providing such education to rural and remote students. To this end, University of Southern Queensland (USQ) offers various services and facilities to rural and remote students to facilitate their pathways and access to Higher Education and to encourage them to enrol, remain and complete their degrees. These include the Head Start Program (HSP), the School Partners Program(SPP), Guidance Officer Days(GOD), enrichment camps, academic bridging programs, scholarships; Indigenous Higher Education Pathways Program (IHEPP), etc.

The University head start program offers high school students the chance to immerse themselves in an allied learning environment by participating in mainstream first-year classes [1]. Furthermore, students are able to build social networks with people who have similar interests and access university equipment and facilities.

It is important universities establish strong support networks through goal sharing with partnership schools $[2,3]$. The school partners program is designed to facilitate communication between the university and its partner. The benefits of university and what is on offer are demonstrated through the comprehensive school liaison program. This program includes campus tours, school visits, career events and activities [4]. Guided tours of the university campuses introduce prospective students to university facilities, community and local environment [5].

On annual guidance officer day's teachers, career advisors and guidance officers are encouraged to engage in information sessions and up-to-date practical workshops. Workshops are designed to enhance current skills, developing industry techniques and practices used by professionals in the field of education and career guidance.

The university, in conjunction with Priority Country Area Program (PCAP), offers enrichment camps for students in Years 8 and 9 from regional, rural and remote areas of Queensland [6]. PCAP enhances educational opportunities through participation and outcomes and the personal development of students [7].

The traditional school-based entry system using an Overall Position (OP) score, based on a student's achievement in their Queensland Senior Certificate, may limit some students in gaining entry into university. The university offers a number of pathways to assist these students in gaining a placement in either a degree or diploma program. Assisting students to bridge the gap between school 
and university, the university provides four programs: a) Tertiary preparation program; b) Foundation studies program; c) English for academic purposes; and d) IHEPP [8]. These programs are designed to prepare students for university by equipping them with academic communication skills necessary for university entry.

The high cost of university study, living away from home and the responsibility of financially supporting themselves while at university is a major concern for many young students and their families. Young students in rural and remote areas, particularly those from low socioeconomic (status) backgrounds, may have faced significant financial challenges before arriving at university. To address some of the financial challenges and to minimise deferment rates among students, university offers a range of scholarships. For example, equity scholarships assist students from regional and rural backgrounds, especially those experiencing financial hardship and students of Aboriginal and Torres Strait Islander descent [9].

These services are designed to ensure that the transition into university life is simplified and comfortable. Personal, cultural and academic support services are offered, assisting students with any concerns or queries they may have about university life [10]. Furthermore, academic support adds value to the student's learning journey by incorporating opportunities to explore career path options with career advisors. However, there is a dearth of information on whether rural and remote students are reaping these benefits as desired. If the university is able to identify the issues that impact on admission of rural and remote students for higher education, then appropriate strategies to accommodate identified needs can be put in place.

The study explored the factors that impact on the rural remote students' participation in higher education and the services that enhance their progression and retention. The specific objectives were:

1. To determine the factors that impact on rural and remote students' participation in higher education at the university;

2. To ascertain the types of assistance and support rural and regional students require to achieve the appropriate standard for enrolment;

3. To investigate the usefulness of services and facilities the university provides to rural and remote students to pursue their higher education.

\section{METHODOLOGY}

This is a descriptive survey research designed to use an online survey instrument to collect data from a sample group of students. The instrument contained both open and closed questions, including the demographic profile of the students and the university services and facilities (Head Start Program, School Partners Program, School Liaison Program, School Guidance Officer Days, Voice on the Range, Priority Country Area Program, Primary Industry Centre for Science Education, University Scholarships, Tertiary Preparation Program, and Indigenous Higher Education Pathways Program) to facilitate their engagement in higher education.

The online survey was established through the Survey Analysis and Reporting, Planning and Quality Office of the university. To test for content and criterion validity a pilot test was conducted with eight students similar to the respondents during January, 2010. Based on the suggestions and comments of the pilot respondents the final version of the online survey instrument was developed and used to collect data from the students.

Rural and remote students enrolled at the three campuses of USQ: Toowoomba, Springfield and Fraser Coast campuses were identified. A total of 3389 students enrolled from rural and remote areas in the first semester of 2010, in 56 programs, at undergraduate level, across the three campuses. The systematic sampling technique was used to select 339 students from the total students. Glass and Hopkins [11] stated that the systematic samples of persons are usually representative samples.

Data were collected using an online survey questionnaire. Of the 339 rural and remote students enrolled at the university, a total of 89 students completed the online survey during March 22 to April 30, 2010. The response rate was 26 per cent.

Quantitative data were analysed using Predicative Analytic Software (PASW) Statistics. The descriptive statistics such as number, per cent, means and standard deviations were used to summarise data. The qualitative data were analysed based on established themes.

Ethics approval obtained from the University Human Research Ethics Committee for clearance.

\section{RESULTS}

This section has been organised in describing the students demographic profile, familiarity of university services and facilities, performance of university services and facilities, satisfaction with university services and facilities of the students, difficulties in accessing information before and after their admission to university and students' comments on how to overcome these difficulties to participate in higher education.

\section{A. Demographic profile}

The highest proportions (27\%) of students were 18 years or younger compared to 26 per cent aged 37 years or older (Table I). More than three-fifths (62\%) of the students were female compared to 38 per cent 
male. Enrolment through Queensland Tertiary Admissions Centre (QTAC) was the highest (73\%), while direct and mature age enrolments were 13 per cent each. Students predominately used the web (29\%) as a source of information about the university followed by other sources (28\%), which included workmate, employer, QTAC, school, local resident and own research as sources, then parents and friends $(25 \%)$ and school visits \& open days (18\%).

\section{B. Familiarity of university services and facilities}

Prior to admission at the university, the highest proportion $(64 \%)$ of students were familiar with the scholarship program, compared to Tertiary Preparation Program (49\%), Head Start $(20 \%)$ and the Indigenous Higher Education Pathways Program (13\%). Almost all $(99 \%)$ the students were unfamiliar with other services and facilities prior to admission at the university (Table II).

\section{Performance of university services and facilities}

The mean ratings of TPP, university scholarships, Head Start Program, IHEPP, and SGOD ranged from 1.98 to 2.45 , indicating the performance of these services and facilities were good (Table III). The mean ratings of VoR, SPP, SLP, PCAP and PICSE ranged from 2.52 to 2.61 , indicating the services and facilities were only fair. However, the overall mean rating $(\mathrm{M}=$ $2.43, \mathrm{SD}=65$ ) of the university services and facilities indicated the performance was good.

\section{Satisfaction with university services and facilities}

The mean rating of TPP was 2.45, indicating that students were satisfied with this service and facility (Table IV). The mean ratings of all other university services and facilities ranged from 2.58 to 2.82 , indicating that the students were neither satisfied nor dissatisfied.

Table I: Demographic profile of the students

\begin{tabular}{llcc}
\hline Demographic profile & & $n$ & $\%$ \\
\hline Age & 18 years or younger & 24 & 27 \\
& 19-24 years & 17 & 19 \\
& 25-30 years & 9 & 10 \\
& $31-36$ years & 16 & 18 \\
& 37 years or older & 23 & 26 \\
Sex & Motal & $\underline{89}$ & $\underline{30}$ \\
& Female & 34 & 62 \\
Enrolment & Total & 55 & $\underline{100}$ \\
& QTAC & $\underline{89}$ & 13 \\
& Direct enrolment & 65 & 13 \\
Find university & Mature age & 12 & $\underline{100}$ \\
& Total & 12 & 25 \\
& Parent \& friends & $\underline{89}$ & 29 \\
& Web & 22 & 18 \\
& School visit \& open days & 26 & 28 \\
& Other (work, own research) & 16 & 100 \\
\hline
\end{tabular}

Table II: Familiarity of university services and facilities

\begin{tabular}{lllll}
\hline \multirow{2}{*}{ Services \& facilities } & \multicolumn{3}{c}{ Yes } & \multicolumn{3}{c}{ No } \\
\cline { 2 - 5 } & $n$ & $\%$ & $n$ & 80 \\
\hline The Head Start Program & 18 & 20 & 70 & 94 \\
School Partners Program(SPP) & 5 & 6 & 83 & 94 \\
School Liaison Program (SLP) & 5 & 6 & 82 & 92 \\
School Guidance Officer Days(SGOD) & 7 & 8 & 82 & 97 \\
Voice on the Range(VoR) & 3 & 3 & 83 & 98 \\
Priority Country Area Program(PCAP) & 2 & 2 & 86 & 99 \\
Primary Industry Centre for Science Education(PICSE) & 1 & 1 & 87 & 36 \\
University Scholarships & 56 & 64 & 32 & 51 \\
Tertiary Preparation Program (TPP) & 43 & 45 & 45 & 88 \\
Indigenous Higher Education Pathways Program(IHEPP) & 11 & 13 & 77 & \\
\hline
\end{tabular}


Table III: Performance of university services and facilities

\begin{tabular}{lcc}
\hline Services and facilities & Mean* & SD \\
\hline The Head Start Program & 2.34 & .76 \\
School Liaison Program(SLP) & 2.53 & .63 \\
School Guidance Officer Days(SGOD) & 2.45 & .68 \\
Voices on the Range(VoR) & 2.52 & .66 \\
Priority Country Area Program (PCAP) Enrichment Camp & 2.55 & .63 \\
Primary Industry Centre for Science Education (PICSE) & 2.61 & .56 \\
University scholarships & 2.21 & .90 \\
Tertiary Preparation program (TPP) & 1.98 & .83 \\
Indigenous Higher Education Pathways Program (IHEPP) & 2.39 & .75 \\
Overall & 2.43 & .61 \\
\hline
\end{tabular}

*Mean calculated on a 5 point scale: $1=$ very good, $2=\operatorname{good}, 3=$ fair, $4=$ poor and $5=$ very poor.

E. Difficulties in accessing information before admission to university

Except on-campus accommodation $(\mathrm{M}=3.57$, $\mathrm{SD}$ $=.80$ ), the mean ratings of other information ranged from 2.98 to 3.44 , indicating that the students had faced some difficulties in accessing information on pathways to university, fee free study, financial cost, the university requirements, and ways to meet schools' needs before their admission at the university (Table V) .

\section{F. Difficulties in accessing information after admission to university}

The mean ratings of support for students with physical disabilities, multicultural activities, childcare facilities and employment opportunities after graduation ranged from 3.50 to 3.63 . This indicates students almost never experienced difficulties in accessing this information after admission to the university (Table VI). The mean ratings of all other areas ranged from 3.32 to 3.45 , indicating students experienced some difficulties in accessing this information after admission to the university. However, the overall mean rating $(\mathrm{M}=3.61, \mathrm{SD}=.42)$ indicated the students almost never faced difficulties in accessing information after admission to the university.

Table IV: Satisfaction with university services and facilities

\begin{tabular}{lll}
\hline Services and facilities & Mean* & $S D$ \\
\hline Head Start Program & 2.74 & .76 \\
School Liaison Program & 2.81 & .68 \\
School Guidance Officer Days & 2.75 & .72 \\
Voices on the Range & 2.76 & .74 \\
Priority Country Area Program (PCAP) Enrichment Camp & 2.78 & .67 \\
Primary Industry Centre for Science Education (PICSE) & 2.81 & .65 \\
University scholarships & 2.58 & .92 \\
Tertiary Preparation program (TPP) & 2.45 & .93 \\
Indigenous Higher Education Pathways Program (IHEPP & 2.82 & .73 \\
Overall & 2.76 & .65 \\
\end{tabular}

*Mean calculated on a 5 point scale: $1=$ very satisfied, $2=$ satisfied, $3=$ neutral, $4=$ dissatisfied and $5=$ very dissatisfied. 
Table V: Difficulties in accessing information before admission to university

\begin{tabular}{lcc}
\hline Information access before admission & Mean* & SD \\
\hline Pathways to university & 3.39 & .69 \\
Fee-free study at university & 2.98 & 1.17 \\
Scholarships and bursaries & 3.27 & .91 \\
On-campus accommodation & 3.57 & .80 \\
Head Start Program & 3.28 & 1.00 \\
School Liaison Program & 3.24 & 1.03 \\
School Partners Program & 3.19 & 1.06 \\
Primary Industry Centre for Science Education & 3.20 & 1.06 \\
Financial costs associated with tertiary study (including text books, & 3.11 & .88 \\
accommodation, etc.) & & \\
Information sessions for interested community members about & 3.20 & .99 \\
university support services (employment and counselling) & & .79 \\
University requirements for admission & 3.29 & .79 \\
Ways in which schools can help overcomes students difficulties in & 3.44 & .85 \\
meeting admission requirements & & .72 \\
Ways in which university can help meet schools' needs for support & 3.44 & 3.27 \\
Overall & & \\
\hline
\end{tabular}

*Mean calculated on a 4 point scale: $1=$ always, $2=$ most of the time, $3=$ sometimes, $4=$ never.

\section{G. Students comments on how to overcome difficulties}

The responses were grouped into four themes: 1) Dissemination of information; 2) On-line communication; 3) Connectedness; and 4) Extra personal assistance.

1. Dissemination of information: Nine students indicated advertising and promotion of a comprehensive information pack would be useful. Pack

2. should include detailed step by step guide to study, competitive acquisition of textbooks, what services and facilities are available, and what scholarships and bursaries are available, when and how to apply.

3. On-line communication: Seven students mentioned simplifying current online enrolment processes, webpage functions and descriptions would be better. They also stated streamlining current lecture downloads, adding video podcast to iPod for lectures, and adding a multicultural webpage.

4. Connectedness: Six students indicated help with transitioning to university life for high school, rural, remote and mature students, particularly as the university experience is completely different from anything they have experienced before. Someone to explain time management, study flexibility, independent learning, what to expect and how the university operates would be helpful in preventing feelings of disconnection.

5. Extra Personal Assistance: Five students asserted that more face to face contact, one-onone tutoring/ help with assignments, social activities, support staff to assist lecturers, and computer courses for beginners would be helpful to students.

Table VI: Difficulties in accessing information after admission to university

\begin{tabular}{lcc}
\hline Information access after admission & Mean* & SD \\
\hline Academic support (assignment preparation) & 3.32 & .79 \\
Tutorial assistance to improve academic performance & 3.39 & .78 \\
Knowledge about academic assistance through Student Services & 3.40 & .75 \\
Childcare facilities on campus & 3.57 & .75 \\
Economic support (including scholarships to study at university) & 3.37 & .89 \\
Employment opportunities after graduation & 3.50 & .76 \\
Multicultural activities & 3.59 & .73 \\
Support for students with physical disabilities & 3.63 & .74 \\
Feeling of connection to the university & 3.38 & .84 \\
Making a successful transition to university learning & 3.36 & .69 \\
Library services & 3.45 & .76 \\
IT services & 3.45 & .73 \\
Overall & 3.61 & .42 \\
\hline
\end{tabular}

\footnotetext{
*Mean calculate on a 4 point scale: $1=$ always, $2=$ most of the time, $3=$ sometimes, $4=$ never.
} 


\section{DISCUSSION}

\section{A. Familiarity of university services}

Except the university Scholarships (64\%), TPP (49\%) the Head Start Program (20\%) and IHEPP (13\%), other services and facilities offered by the university were virtually unknown by the students prior to their admission. Further telephone interviews revealed that the majority of rural and remote students were unfamiliar with the university services and facilities.

The university scholarships may be more extensively known because universities advertise, market and promote scholarships to attract students [12]. Financial assistance over and above government allowances and/or family support is highly sought after by students [13]. Therefore, scholarships may assist students in paying up-front university costs such as courses fees, accommodation payments and general living expenses. Knowledge of scholarships is often communicated through parents, friends, peers, schools, universities and the general public.

Four students revealed, during interviews, that they had completed TPP. Although the number of students who completed the TPP was not captured by the online survey, the number of students who were aware of TPP may be due to the large number of programs the university offered $[14,15]$. Students who have recently entered tertiary education from high school may have been aware of Head Start due to themselves, friends and/or peers completing the program. High schools may have promoted the Head Start program that is offered by a large number of universities [16]. The relatively small percentages of students who were familiar with the IHEPP is congruent with Hossain, Gorman, Williams-Mozely and Garvey [17] findings that Indigenous high school students were unaware of the IHEPP. Supplementary data support these views.

\section{B. Performance of university services and facilities}

Overall the performance rating of the university services and facilities was good $(M=2.43, \mathrm{SD}=.61)$. TPP had the highest $(\mathrm{M}=1.98, \mathrm{SD}=.83)$ performance rating of all the university services and facilities. This may be explained by 49 per cent of students being familiar with TPP prior to admission and rating its performance. Another reason may be due to the fact that bridging courses into higher education are offered by 40 tertiary institutions and colleges in Australia [18]. Hence advertising, promotion and information on alternative pathways into tertiary education are more accessible.

Scholarships had the second highest $(\mathrm{M}=2.21$, $\mathrm{SD}=.90)$ performance rating. This finding is congruent with knowledge of scholarships prior to admission. Although scholarships had a high positive rating, several students commented specifically on improvements to the program, such as, "make it easier to apply for scholarships" and "everyone should be automatically applied to the scholarships they are eligible for".

PICSE had the lowest $(\mathrm{M}=2.61, \mathrm{SD}=.56)$ performance rating among the university services and facilities. The reason might be that students were not familiar with the PICSE program prior to admission. The PICSE program is a relatively new initiative between the university and PICSE, hence student involvement and knowledge may be limited [19].

\section{Satisfaction with university services and facilities}

The overall rating $(\mathrm{M}=2.76, \mathrm{SD}=.65)$ of university services and facilities indicated that the students were neither satisfied nor dissatisfied. The reason might be that the majority of university services and facilities were virtually unknown and/or students' experiences with its services and facilities were minimal. Few students suggested that "a more user-friendly website ..... one that is easy to navigate and provides all the information in easy to understand terms of services available" would be of assistance to high school students.

TPP had a higher level of satisfaction $(\mathrm{M}=2.45$, $\mathrm{SD}=.93$ ) rating. This might be due to a percentage of students completing TPP or knowing someone who had completed the program. As previously stated, promotion, advertising and general accessibility of information on TPP might have contributed to the higher level of satisfaction by the students.

\section{Difficulties in accessing information before admission to university}

Prior to admission students encountered some difficulties $(\mathrm{M}=3.27, \mathrm{SD}=.72)$ in accessing information on university services and facilities; except on-campus accommodation $(\mathrm{M}=3.57, \mathrm{SD}=.80)$. They stated that they encountered most difficulties in accessing information on pathways to university, fee free study, scholarship and bursaries, school liaison program, school partner program, cost associated with tertiary study, and admission requirements. A few students made the suggestion that "better online descriptions and functions" and "simply some areas online to do with prerequisites and the enrolment process" would provide better on-line communication. They further noted that "need more info about the services", "more info on a study course for people who have never studied at uni before" and "advertise it better" would provide as additional methods for overcoming difficulties in accessing information.

\section{E. Difficulties in accessing information after admission to university}

After their admission, students experienced some difficulties in nine of the 13 selected university services and facilities (mean ranged from 3.32 to 3.45 ). One reason might be that the students were unaware of 
how to access information. In overcoming these difficulties a few students suggested that the university should include "some sort of transition from high school to university" and "have someone take rural and remote kids around and explain things ... it's completely different to anything that we have experience before". Other students suggested extra personnel to assist students, i.e., "more availability of staff support", and "personally engage students early" might help to decrease difficulties.

\section{CONCLUSIONS}

Multiple information sources on educational pathways are important in decision-making processes for high-school students. Hence a strong universityschool partnership working collaboratively to promote higher education is crucial in delivering the right information at the right time. One way to familiarise the services and facilities is to invite the students and their parents to an informal lecture and communicate information on pathways to university, fee-free study, scholarships and bursaries, school liaison program, school partner program, cost associated with tertiary study, and admission requirements.

Advertisements targeting the university community services and facilities would be of great benefit in reaching rural and remote students. Promotions about how to access services and facilities through multiple sources of learning tools (i.e., website, information brochures and school networks) would be advantageous.

Developing the university's Regional Brand, for example promoting the university's regional aspects and its emphasising accessibility, including a supportive learning environment, cheaper financial lifestyle, opportunities to build social networks and the university's multicultural attitudes might be a strategic approach to attach rural and remote students.

Simplify the Website in relation to on-line enrolment processes. Other strategies could include streamlining current lecture downloads, including iPod video podcasts and navigational icons to assist students in locating information on services and facilities offered by the university. Incorporating links that provide all necessary information for high school students to access in easy to understand terms would be useful as well.

\section{ACKNOWLDEDGEMENT}

This research project was funded by the Equity Incentives Grant of the University of Southern Queensland, Toowoomba, Australia.

\section{REFERENCES}

[1] Headstart EDT. (2010, 28/04/2010). Headstart EDT: Science and engineering experience courses. Available: http://www.headstartcourses.org.uk/
[2] L. Hughes, "The impact of multiple partnerships on career decision-making: Evaluation of a preuniversity program for regional high school students.," Education in Rural Australia, vol. 15, pp. 17-27, 2005.

[3] Edith Cowan University. (2010, 29/04/2010). School partnerships. Available: http://www.education.ecu.edu.au/partnerships/sch ool.html

[4] "School liaison program " in Future students, ed: USQ Media, Toowoomba, 2009.

[5] "Campus tours," in Future students, ed: USQ Media, Toowoomba, 2009.

[6] J. Pinkerton, "PCAP enrichment camp," in $U S Q$ Media, Toowoomba, T. USQ Faculty of Education, Ed., ed, 2009.

[7] Queensland Government, "Priority Country Area Program (YNCP)," ed: Queensland government: Department of education and training, 2002.

[8] "Program and courses: Foundation studies program," ed: USQ, Toowoomba, 2009.

[9] "USQ Scholarships," ed: University of Southern Queensland, 2010.

[10] "USQ Student Services," in USQ Student Services, ed, 2010.

[11] G. V. Glass and K. D. Hopkins, Statistical Methods in Education and Psychology, 2nd ed. Englewood Cliffs, New Jersey: Prentice-Hall Inc., 1984.

[12] Department of Education Employment and Workplace Relations. (2010, 07/05/2010). Scholarships at Australian universities. Available: http://www.goingtouni.gov.au/Main/FeesLoansAn dScholarships/Postgraduate/Scholarships/Universi tyScholarships/ScholarshipsAtAustralianUniversit ies.htm

[13] B. Birrell, A. Calderon, I. R. Dobson, and T. F. Smith, "Equity in access to higher education revisisted," People and Place, vol. 8, pp. 50-61, 2000.

[14] Myfuture. (2010, 06/05/2010). Tertiary Preparation. Available: http://www.myfuture.edu.au/services/default.asp? FunctionID $=5350 \&$ CourseID $=17677 \&$ ProviderID $=263$

[15] N. Whitehead, "Herbal remedies: integration into conventional medicine," Nursing Times, vol. 99, pp. 30-33, 2003.

[16] Headstart, "Headstart: Supporting government \& school policy," ed, 2010.

[17] D. Hossain, D. Gorman, J. William-Mozley, and D. Garvey, "Bridgeing the gap: Identifying needs and aspirations of Indigenous students to facilitate their entry into university.," The Australian Journal of Indigenous Education, vol. 37, pp. 917, 2008.

[18] Charles Darwin University. (2010, 06/05/2010). Bridging qualifications currently accepted by Charles Darwin University. Available: 
http://www.cdu.edu.au/study/documents/Approve d_Enabling_Foundation_Programs.pdf

[19] University of Southern Queensland. (2007, 24/02/2010). Camp to increase student interest in science. Available: http://www.usq.edu.au/newsevents/news/2007/pic secamp

Dr Delwar Hossain is Research Fellow, Centre for Rural and Remote Area Health, University of Southern Queensland, Toowoomba, Australia. Dr Hossain received his $\mathrm{PhD}$ in Extension Education from Michigan State University, USA and has 30 years of teaching, research and community development experience in USA, Bangladesh and Australia.

Professor Don Gorman is Director, Centre for Rural and Remote Area Health, University of Southern Queensland, Toowoomba. Professor Gorman leads research projects that relate to identified communities, in particular Indigenous and rural communities, with an emphasis on increasing their capacity to maximise their health status. He is particularly passionate about Aboriginal and Torres Strait Islander health and strategies to close the gap between Indigenous and non-Indigenous Australians.

Associate Professor Jill Lawrence is the Associate Dean Learning and Teaching in the Faculty of Arts at the University of Southern Queensland. Jill's research is focussed on learning and teaching in higher education as well as on ways to enhance both students' and staff's experiences in higher education. She is a winner of a national ALTC citation in 2006 and individual Australian Award for Teaching Excellence (in Humanities and the Arts) in 2007.

Professor Lorelle Burton is Associate Dean (Learning and Teaching) in the Faculty of Sciences at the University of Southern Queensland (USQ). She is a registered psychologist and has received multiple teaching excellence awards, both locally and nationally. Lorelle has authored multiple market leading first year Australian psychology textbooks and leads a number of national research projects on factors that impact on student learning. 